\title{
Detecting heterogeneous risk attitudes with mixed gambles
}

\author{
Luís Santos-Pinto • Adrian Bruhin • José Mata • \\ Thomas Åstebro
}

\begin{abstract}
We propose a task for eliciting attitudes toward risk that is close to real-world risky decisions which typically involve gains and losses. The task consists of accepting or rejecting gambles that provide a gain with probability $p$ and a loss with probability $1-p$. We employ finite mixture models to uncover heterogeneity in risk preferences and find that (i) behavior is heterogeneous, with one half of the subjects behaving as expected utility maximizers, (ii) for the others, reference-dependent models perform better than those where subjects derive utility from final outcomes, (iii) models with sign-dependent decision weights perform better than those without, and (iv) there is no evidence for loss aversion. The procedure is sufficiently simple so that it can be easily used in field or lab experiments where risk elicitation is not the main experiment.
\end{abstract}

Keywords Individual risk-taking behavior - Latent heterogeneity - Finite mixture models $\cdot$ Reference-dependence $\cdot$ Loss aversion

JEL Classification C91 D D 1

L. Santos-Pinto $(\varangle) \cdot$ A. Bruhin

Faculty of Business and Economics (HEC Lausanne), University of Lausanne,

Internef 535, 1015 Lausanne, Switzerland

e-mail: luispedro.santospinto@unil.ch

A. Bruhin

e-mail: adrian.bruhin@unil.ch

J. Mata

Nova School of Business and Economics, INOVA, Universidade Nova de Lisboa,

Lisbon, Portugal

e-mail: jmata@novasbe.pt

T. Åstebro

HEC-Paris, Jouy-en-Josas, France

e-mail: astebro@hec.fr 


\section{Introduction}

Decisions made when agents confront risky alternatives are conventionally explained by expected utility (EU) theory. However, evidence from the field and the lab shows that, on average, subjects' behavior deviates from EU predictions (see Schoemaker 1982; Starmer 2000 for reviews). Furthermore, studies looking at individual decisions under risk like Lattimore et al. (1992) and Hey and Orme (1994) found heterogeneity in behavior. These studies typically found that some subjects behave in line with EU, but most do not. Recent studies that use finite mixture models to take the presence of EU and non-EU types into account report similar results (Bruhin et al. 2010; Conte et al. 2011). ${ }^{1}$

Ignoring this behavioral heterogeneity may lead to biased conclusions. For instance, studies that attempt to discriminate between alternative theories of non-EU behavior assuming a representative decision maker may suffer from such biased conclusions. Failure to acknowledge that a significant proportion of subjects may behave according to EU leads to confounded parameter estimates that do not correctly reflect the nonEU subjects' behavior. Furthermore, acknowledging behavioral heterogeneity may also be important for field and lab experiments that are increasingly being used in a diversity of fields (Levitt and List 2007; Falk and Heckman 2009). Rather than assuming a representative decision maker-who is typically postulated to act according to EU- experimental researchers would benefit from being able to identify in their samples who acts according to EU and who does not. Accounting for this heterogeneity may prove to be important to explain what may seem to be odd patterns of choices.

We propose a method that allows the experimenter to economically elicit information about risk preferences, while accounting for the presence of both EU and non-EU subjects. Due to its simplicity, our procedure can be easily used for characterizing EU and non-EU subjects in field or lab experiments, even when elicitation of risk preferences is not the main concern.

The proposed method consists of a lottery choice task in which subjects accept or reject a series of simple two-outcome mixed gambles, i.e., gambles involving a gain and a loss. The task has a clear-cut reference point, uses 30 decisions per subject, and applies monetary incentives in a symmetric way across the gain and loss domains. The use of mixed gambles yields data that are rich enough to control for heterogeneity in risk attitudes and to discriminate between reference-dependent and non-referencedependent models of choice under risk. ${ }^{2}$

We use finite mixture models to simultaneously segregate EU from non-EU types and compare the descriptive power of the different models that depart from EU max-

\footnotetext{
${ }^{1}$ Harrison and Rutström (2009) apply finite mixture models too in order to distinguish EU from nonEU behavior. However, they classify decisions instead of subjects. Therefore, their results are not directly comparable to Bruhin et al. (2010) and Conte et al. (2011).

2 Mixed gambles bring the experimental task closer to real-world risky decisions than most previous experimental work. Real-world decisions typically involve gain-loss gambles, but most prior experimental research on the elicitation of risk attitudes used lotteries involving only gains (e.g., Brunner et al. 2007; Ebert and Wiesen 2009; Deck and Schlesinger 2010) or lotteries involving either only gains or only losses (e.g., Holt and Laury 2002; Fehr-Duda et al. 2010; Bruhin et al. 2010).
} 
imization. Finite mixture models endogenously classify subjects making noisy decisions into a pre-defined number of distinct preference types. They require substantially less parameters than estimations at the individual level but are still able to account for the most important aspect of heterogeneity, namely, the existence of such distinct preference types. Therefore, mixture models represent a neat compromise between parsimony and flexibility. These models are relatively new in decision theory but have previously been used to uncover different types of behavior in complex decision situations (El-Gamal and Grether 1995; Stahl and Wilson 1995; Houser et al. 2004; Houser and Winter 2004).

To model non-EU behavior, we focus on four theories: rank-dependent utility (RDU), weighted utility (WU), prospect theory (PT), and salience theory (ST). In RDU, people evaluate utility over final wealth levels, and the only deviation from EU is probability weighting (Quiggin 1982). In WU, people also evaluate utility over final wealth levels, and the only deviation from EU is outcome weighting (Chew 1983). In PT there are multiple deviations from EU: people evaluate utility relative to a reference point, they can exhibit diminishing sensitivity to monetary gains and losses, they may apply different probability weights in the gain and loss domains, and they may be averse to losses (Kahneman and Tversky 1979; Tversky and Kahneman 1992). In ST, people deviate from EU in similar ways as in PT but overweigh the probabilities of salient payoffs (Bordalo et al. 2012). ${ }^{3}$

Our main results are as follows. First, individual behavior is heterogeneous with roughly $50 \%$ of the subjects behaving as expected utility (EU) maximizers and $50 \%$ as non-EU maximizers. There is a clean segregation into types, i.e., almost all subjects are unambiguously classified either as EU or non-EU. Second, models where the nonEU types have reference-dependent preferences, i.e., they derive utility from gains and losses relative to a reference point, perform better than those where non-EU types derive utility from final outcomes. Third, the individual classification into EU and nonEU types remains the same regardless of whether the non-EU types are specified by PT or ST. Fourth, models that allow for domain-specific decision weights outperform models which constrain the decision weights' pattern to be the same for gains and losses. Fifth, there is no evidence for loss aversion.

The paper proceeds as follows. Section 2 describes the experimental design. Section 3 introduces the different theories for non-EU behavior. Section 4 explains our estimation strategy. Section 5 presents the results. Finally, Sect. 6 concludes the paper.

\footnotetext{
3 Most of prior experimental work on reference-dependent models has been limited to testing a subset of the behavioral features of PT. For example, Abdellaoui (2000) and Bruhin et al. (2010) use lotteries involving either only gains or only losses and estimate probability distortion parameters for the gain and loss domains but do not estimate a loss aversion parameter since that is neither feasible nor meaningful. Tversky and Kahneman (1992) and Abdellaoui et al. (2007) study all features of risk preferences proposed by PT but use hypothetical choices. Abdellaoui et al. (2008) use real incentives for lotteries with only gains but not for lotteries with only losses or with gains and losses. As far as we know, there are only two other studies that analyze all aspects of PT using monetary incentives for all types of lotteries: Harrison and Rutström (2009) and Tanaka et al. (2010).
} 


\section{Experimental design}

The experiment was performed at the University of Zurich. All subjects were students of the University of Zurich or the Swiss Federal Institute of Technology Zurich (ETH), recruited via ORSEE (Greiner 2004). Economists and psychologists were excluded from the subject pool. To make sure subjects fully understood the procedures and the payoff consequences of the available actions, each subject had to read a detailed set of instructions before the session started and was allowed to ask clarifying questions.

Our lottery choice task must accomplish two goals: (1) distinguish EU from non-EU types and (2) provide data rich enough to estimate fully specified versions of different non-EU models. Moreover, cognitively the lotteries should be as simple as possible and have a clear-cut reference point.

We offer subjects a task with three sets of choices. Each set of choices was designed in prize-list style with 10 decision rows. Each decision row was a choice between a mixed gamble (accept) and a certain amount of zero (reject). The certain amount is kept fixed across the three sets of choices so subjects see it as a reference point.

Let $X_{i}^{j}$ denote gamble $i$ in set of choices $j$, where $i \in\{1,2, \ldots, 10\}$ and $j \in\{1,2,3\}$. Let $E\left(X_{i}^{j}\right)$ and $V\left(X_{i}^{j}\right)$ denote, respectively, the mean and variance of gamble $X_{i}^{j}$. The first set of choices contains ten gambles each offering a $10 \%$ probability of a large loss and a $90 \%$ probability of a small gain. Gamble $i$ in the first set of choices is $X_{i}^{1}=(0.1,(15-i) x ; 0.9,-x)$, where $x>0$. The second set of choices contains ten gambles each offering a $50 \%$ probability of a moderate loss and a $50 \%$ probability of a moderate gain. Gamble $i$ in the second set of choices is $X_{i}^{2}=(0.5,1.2 x ; 0.5,-0.2 i x)$. Finally, the third set of choices contains ten gambles each offering a $90 \%$ probability of a small loss and a $10 \%$ probability of a large gain. Gamble $i$ in the third set of choices is $X_{i}^{3}=(0.9, x ; 0.1,-(3+i) x)$.

The gambles' means satisfy

$$
E\left(X_{i}^{1}\right)=E\left(X_{i}^{2}\right)=E\left(X_{i}^{3}\right)=\frac{6-i}{10} x, \text { for all } i
$$

that is, the mean of the $i$-th gamble is the same across the three sets of choices and equal to $(6-i) x / 10$. Hence, the ten gambles in each set of choices are ordered in terms of expected value. The expected value is positive for the first five gambles, zero for the sixth gamble, and negative for the last four gambles. Hence, subjects should begin each set of choices by preferring the gamble and then switching to the certain amount.

The gambles' variances satisfy the following conditions:

$$
V\left(X_{i}^{2}\right)<V\left(X_{i}^{1}\right)<V\left(X_{i}^{3}\right), \quad \text { if } i \leq 5,
$$

and

$$
V\left(X_{i}^{2}\right)<V\left(X_{i}^{1}\right)=V\left(X_{i}^{3}\right), \quad \text { if } i=6,
$$


and

$$
V\left(X_{i}^{2}\right)<V\left(X_{i}^{3}\right)<V\left(X_{i}^{1}\right), \quad \text { if } i \geq 7
$$

This lottery choice task allows us to distinguish EU from non-EU behavior. According to EU an individual can have linear, concave, or convex utility defined over final wealth states reflecting neutrality, aversion, or love for risk. Irrespective of variance, a risk neutral EU person accepts all gambles with positive mean and reject all gambles with negative mean across the three sets of choices. Depending on variance, a risk averse EU person rejects all gambles with non-positive mean and rejects some gambles with positive mean across the three sets of choices. Finally, depending on variance, a risk-loving EU person accepts all gambles with non-negative mean and some gambles with negative mean across the three sets of choices.

The task also allows us to estimate fully specified versions of different non-EU models. The varying outcome probabilities across the three sets of choices allow us to identify subjective decision weights. For example, a PT subject characterized by a linear utility function and inverse s-shape probability weighting would accept less than six gambles in the first set of choices, six gambles in the second set of choices, and more than six gambles in the third set of choices. Moreover, since all gambles involve gains and losses we can not only distinguish reference-dependent from non-referencedependent models but also identify the degree of loss aversion in reference-dependent models.

We run the experiment with two levels of stakes ( $x=5 \mathrm{CHF}$ and $x=10 \mathrm{CHF}$ hereafter called the $1 \mathrm{x}$ stake and $2 \mathrm{x}$ stake conditions, respectively). Subjects in the $1 \mathrm{x}$ stake condition are faced with the three sets of choices displayed in Tables 1, 2 and 3 (the columns with expected value and the variance of the lotteries were not shown to subjects). In the $2 \mathrm{x}$ stake condition, stakes are twice as high.

The order of the three sets of choices was randomly assigned and counterbalanced. A total of 109 subjects participated in the experiment, 70 in the $1 \mathrm{x}$ stake condition

Table 1 First set of choices (1x stake)

\begin{tabular}{|c|c|c|c|c|c|}
\hline Choice & Lottery $(L)$ & Accept & Reject & $E(L)$ & $V(L)$ \\
\hline 1 & $10 \%$ of $-20 \mathrm{CHF}, 90 \%$ of $5 \mathrm{CHF}$ & & & 2.50 & 56 \\
\hline 2 & $10 \%$ of $-25 \mathrm{CHF}, 90 \%$ of $5 \mathrm{CHF}$ & & & 2.00 & 81 \\
\hline 3 & $10 \%$ of $-30 \mathrm{CHF}, 90 \%$ of $5 \mathrm{CHF}$ & & & 1.50 & 110 \\
\hline 4 & $10 \%$ of $-35 \mathrm{CHF}, 90 \%$ of $5 \mathrm{CHF}$ & & & 1.00 & 144 \\
\hline 5 & $10 \%$ of $-40 \mathrm{CHF}, 90 \%$ of $5 \mathrm{CHF}$ & & & 0.50 & 182 \\
\hline 6 & $10 \%$ of $-45 \mathrm{CHF}, 90 \%$ of $5 \mathrm{CHF}$ & & & 0 & 225 \\
\hline 7 & $10 \%$ of $-50 \mathrm{CHF}, 90 \%$ of $5 \mathrm{CHF}$ & & & -0.50 & 272 \\
\hline 8 & $10 \%$ of $-55 \mathrm{CHF}, 90 \%$ of $5 \mathrm{CHF}$ & & & -1.00 & 324 \\
\hline 9 & $10 \%$ of $-60 \mathrm{CHF}, 90 \%$ of $5 \mathrm{CHF}$ & & & -1.50 & 380 \\
\hline 10 & $10 \%$ of $-65 \mathrm{CHF}, 90 \%$ of $5 \mathrm{CHF}$ & & & -2.00 & 441 \\
\hline
\end{tabular}

The last two columns were not displayed to experimental subjects 
Table 2 Second set of choices (1x stake)

\begin{tabular}{|c|c|c|c|c|c|}
\hline Choice & Lottery $(L)$ & Accept & Reject & $E(L)$ & $V(L)$ \\
\hline 1 & $50 \%$ of $-1 \mathrm{CHF}, 50 \%$ of $6 \mathrm{CHF}$ & & & 2.50 & 12 \\
\hline 2 & $50 \%$ of $-2 \mathrm{CHF}, 50 \%$ of $6 \mathrm{CHF}$ & & & 2.00 & 16 \\
\hline 3 & $50 \%$ of $-3 \mathrm{CHF}, 50 \%$ of $6 \mathrm{CHF}$ & & & 1.50 & 20 \\
\hline 4 & $50 \%$ of $-4 \mathrm{CHF}, 50 \%$ of $6 \mathrm{CHF}$ & & & 1.00 & 25 \\
\hline 5 & $50 \%$ of $-5 \mathrm{CHF}, 50 \%$ of $6 \mathrm{CHF}$ & & & 0.50 & 30 \\
\hline 6 & $50 \%$ of $-6 \mathrm{CHF}, 50 \%$ of $6 \mathrm{CHF}$ & & & 0 & 36 \\
\hline 7 & $50 \%$ of $-7 \mathrm{CHF}, 50 \%$ of $6 \mathrm{CHF}$ & & & -0.50 & 42 \\
\hline 8 & $50 \%$ of $-8 \mathrm{CHF}, 50 \%$ of $6 \mathrm{CHF}$ & & & -1.00 & 49 \\
\hline 9 & $50 \%$ of $-9 \mathrm{CHF}, 50 \%$ of $6 \mathrm{CHF}$ & & & -1.50 & 56 \\
\hline 10 & $50 \%$ of $-10 \mathrm{CHF}, 50 \%$ of $6 \mathrm{CHF}$ & & & -2.00 & 64 \\
\hline
\end{tabular}

The last two columns were not displayed to experimental subjects

Table 3 Third set of choices (1x stake)

\begin{tabular}{|c|c|c|c|c|c|}
\hline Choice & Lottery $(L)$ & Accept & Reject & $E(L)$ & $V(L)$ \\
\hline 1 & $90 \%$ of $-5 \mathrm{CHF}, 10 \%$ of $70 \mathrm{CHF}$ & & & 2.50 & 506 \\
\hline 2 & $90 \%$ of $-5 \mathrm{CHF}, 10 \%$ of $65 \mathrm{CHF}$ & & & 2.00 & 441 \\
\hline 3 & $90 \%$ of $-5 \mathrm{CHF}, 10 \%$ of $60 \mathrm{CHF}$ & & & 1.50 & 380 \\
\hline 4 & $90 \%$ of $-5 \mathrm{CHF}, 10 \%$ of $55 \mathrm{CHF}$ & & & 1.00 & 324 \\
\hline 5 & $90 \%$ of $-5 \mathrm{CHF}, 10 \%$ of $50 \mathrm{CHF}$ & & & 0.50 & 272 \\
\hline 6 & $90 \%$ of $-5 \mathrm{CHF}, 10 \%$ of $45 \mathrm{CHF}$ & & & 0 & 225 \\
\hline 7 & $90 \%$ of $-5 \mathrm{CHF}, 10 \%$ of $40 \mathrm{CHF}$ & & & -0.50 & 182 \\
\hline 8 & $90 \%$ of $-5 \mathrm{CHF}, 10 \%$ of $35 \mathrm{CHF}$ & & & -1.00 & 144 \\
\hline 9 & $90 \%$ of $-5 \mathrm{CHF}, 10 \%$ of $30 \mathrm{CHF}$ & & & -1.50 & 110 \\
\hline 10 & $90 \%$ of $-5 \mathrm{CHF}, 10 \%$ of $25 \mathrm{CHF}$ & & & -2.00 & 81 \\
\hline
\end{tabular}

The last two columns were not displayed to experimental subjects.

and 39 in the $2 x$ stake condition. In order to provide incentive for truthful revelation of preferences, subjects were randomly paid for one of their choices. Each subject received a show-up fee of $10 \mathrm{CHF}$. Since subjects could not walk away from the laboratory making losses, all subjects were endowed with the maximum possible loss they could incur in the experiment (65 CHF in the 1x stake condition and $130 \mathrm{CHF}$ in the $2 \mathrm{x}$ stake condition).

In the laboratory, we are challenged to implement losses that are viewed by subjects as "true losses" and not just lesser gains. In order to minimize a house-money effect and therefore to make losses more real, one week before the experiment took place, subjects who would be assigned to the $1 \mathrm{x}$ stake condition received an email where they were told: "Next week you will participate in an experiment on decision making under risk. You will be paid $10 \mathrm{CHF}$ as compensation for your time spent. Additionally, you will be given 65 CHF and you will keep the 65 CHF with $90 \%$ probability." Subjects 
who would be assigned to the $2 \mathrm{x}$ stake condition received a similar email, the only difference being that $65 \mathrm{CHF}$ was replaced by $130 \mathrm{CHF}$.

The goal of this email was to induce subjects to think that their (probabilistic) reference point regarding rewards from the experiment is close to the actual expected earnings. If this manipulation was successful, then a subject who comes out of the laboratory with less than the expected earnings will feel like he suffered a loss, and one that comes out with more will feel like he has made a gain.

Subjects' earnings were determined after task completion. The roll of a six-sided die determined which of the three sets of choices was relevant for payment. Subsequently, the roll of a ten-sided die indicated the decision row (decisions 1 through 10) relevant for payment. Each subject was paid according to the realizations of the dies and his or her choices (accept or reject). The mean earnings of subjects in the $1 \mathrm{x}$ stake condition were $79.18 \mathrm{CHF}$ and $173.74 \mathrm{CHF}$ in the $2 \mathrm{x}$ stake condition (excluding the $10 \mathrm{CHF}$ show-up fee). Total earnings paid to subjects including show-up fees were 13,409.00 CHF. The experimental instructions are in the Experimental Material Appendix.

\section{Summary statistics}

This section presents summary statistics of subjects' behavior across the three sets of choices. On average, people seem to deviate from EU and there is substantial heterogeneity in choices. Table 4 displays the mean number of accepted gambles in each set of choices (the first row) and the absolute frequencies (the remaining rows).

Table 4 reveals that, on average, subjects deviate from EU behavior. In the first set of choices, subjects accept, on average, 3.69 gambles. Thus, on average, subjects are willing to reject a small stake positive mean gamble to avoid facing a small probability of incurring a large loss (first-order risk averse behavior). In the second set of choices,

Table 4 Number of lotteries accepted across choice sets

\begin{tabular}{lccc}
\hline Acceptance behavior (lottery choice category) & First choice set & Second choice set & Third choice set \\
\hline Average number of lotteries accepted & 3.69 & 5.27 & 6.94 \\
Reject all lotteries & 20 & 1 & 9 \\
Accept 1 , reject 2 to 10 & 11 & 2 & 1 \\
Accept 1 and 2, reject 3 to 10 & 17 & 11 & 4 \\
Accept 1 to 3, reject 4 to 10 & 11 & 13 & 3 \\
Accept 1 to 4 , reject 5 to 10 & 9 & 38 & 3 \\
Accept 1 to 5, reject 6 to 10 & 11 & 20 & 16 \\
Accept 1 to 6 , reject 7 to 10 & 6 & 3 & 5 \\
Accept 1 to 7 , reject 8 to 10 & 1 & 4 & 4 \\
Accept 1 to 8 , reject 9 and 10 & 3 & 2 & 3 \\
Accept 1 to 9 , reject 10 & 2 & 9 & 47 \\
Accept all & 12 & 2 & 4 \\
Multiple switchers & 6 & 109 & 109 \\
Total & 109 & & 5 \\
\hline
\end{tabular}


Table 5 Regression results: number of accepted lotteries
Robust standard errors in parentheses

a indicates significance at $1 \%$

\begin{tabular}{lll}
\hline & $(1)$ & $(2)$ \\
\hline Constant & 3.661 & 3.601 \\
Second set & $(0.298)$ & $(0.384)$ \\
& $1.606^{\mathrm{a}}$ & $1.608^{\mathrm{a}}$ \\
Third set & $(0.359)$ & $(0.362)$ \\
& $3.284^{\mathrm{a}}$ & $3.287^{\mathrm{a}}$ \\
2x stake & $(0.434)$ & $(0.436)$ \\
& & -0.093 \\
Order (2nd) & & $(0.329)$ \\
& & 0.121 \\
Order (3rd) & & $(0.403)$ \\
$R^{2}$ & & 0.152 \\
$\bar{R}^{2}$ & & $(0.382)$ \\
No. subj. & 0.179 & 0.179 \\
No. obs. & 0.174 & 0.167 \\
\hline
\end{tabular}

subjects accept, on average, 5.27 gambles. Hence, on average, subjects accept fiftyfifty gambles with positive mean and reject fifty-fifty gambles with negative mean (risk neutral behavior). Finally, in the third set of choices, subjects accept, on average, 6.94 gambles. Therefore, on average, subjects are willing to accept a small stake negative mean gamble in exchange for a small probability of attaining a large gain (first-order risk-seeking behavior).

The pattern of choices described in the previous paragraph is incompatible with all subjects following EU and making random errors. In contrast to EU, the absolute frequencies vary substantially across the three different sets of choices. The number of subjects who reject at least one gamble with positive mean goes from 68 (out of 109) in the first set of choices to 31 (in the second) and then to 20 (in the third). The number of subjects who accept at least one gamble with negative mean is 18 in the first set of choices, 18 in the second, and 59 in the third. Finally, the number of multiple switchers is $8(6,2$, and 4 in the different skew conditions).

Table 5 shows the results of regressions using the number of accepted gambles as the dependent variable. ${ }^{4}$ Column 1 shows the results of a regression including a constant and two dummies for the second and third choice sets as regressors. The estimates are, of course, consistent with average number of lotteries accepted reported in the first row of Table 4. Moreover, the differences in lottery choice patterns across the three sets of choices are statistically significant: on average, subjects accept more gambles (1.606 and 3.284) in the second and third sets of choices than in the first one.

The regression reported in Column 2 also includes dummy variables to control for the magnitude of the stakes and for the order in which the three sets of choices were

\footnotetext{
4 The regressions reported in Table 5 exclude the eight multiple switchers so that the number of accepted lotteries corresponds to the switching point. The subsequent analysis includes all 109 subjects.
} 
presented to subjects. Since none of these effects are significant, we pool the data with respect to stakes and order from now on.

\section{Decision models}

This section briefly summarizes the four non-EU decision models under consideration. It starts with the non-reference-dependent models, RDU and WU, and then it moves on to the reference-dependent models, PT and ST.

\subsection{Rank-dependent utility}

According to rank-dependent utility (Quiggin 1982), the value of a gamble $X$ which yields a gain of $g>0$ with probability $p$ and a loss of $l<0$ with probability $1-p$ is

$$
\begin{aligned}
R D U(w+X) & =d_{1} u(w+g)+d_{2} u(w+l) \\
& =h(p) u(w+g)+[1-h(p)] u(w+l),
\end{aligned}
$$

where $u(\cdot)$ is the utility function, $h(p)$ is the probability weighting function, and $w$ is the endowment. We specify $u(\cdot)$ using exponential utility, i.e., constant absolute risk aversion:

$$
u(w+x) \begin{cases}\frac{1-\mathrm{e}^{-\beta(w+x)}}{\beta}, & \beta \neq 0 \\ w+x, & \beta=0\end{cases}
$$

where $x$ is the outcome of a gamble. The parameter $\beta$ determines the curvature of the utility function. $\beta>0$ corresponds to risk aversion, $\beta=0$ to risk neutrality, and $\beta<0$ to love for risk. Exponential utility has been widely used in economics, and it generally fits experimental data on utility measurement well (e.g., Abdellaoui et al. 2007).

To model probability weighting, we use the one-parameter probability weighting function in Goldstein and Einhorn $(1987)^{5}$ :

$$
h(p)=\frac{p^{\eta}}{p^{\eta}+(1-p)^{\eta}},
$$

where the parameter $\eta$ determines the degree of probability weighting. When $\eta=1$, there is no probability weighting and we are back to EU. If $\eta \in(0,1)$, the function captures the inverse s-shape pattern where low probabilities are upweighted and high probabilities are downweighted. If $\eta>1$, we have an s-shape pattern where low probabilities are downweighted and high probabilities are upweighted.

\footnotetext{
5 Given that our gambles only have three probability values and that we will measure loss aversion in the PT model, we cannot identify a two-parameter probability weighting function.
} 


\subsection{Weighted utility}

According to weighted utility (Chew 1983) the value of a gamble $X$ which yields a gain of $g>0$ with probability $p$ and a loss of $l<0$ with probability $1-p$ is

$$
W U(w+X)=\frac{p W_{w+g} u(w+g)+(1-p) W_{w+l} u(w+l)}{p W_{w+g}+(1-p) W_{w+l}},
$$

where $u(\cdot)$ is the utility function, which will be the same as with RDU, and $W_{w+g}$ and $W_{w+l}$ are the outcome weights. We specify these outcome weights as $W_{w+g}=e^{\alpha(w+g)}$ and $W_{w+g}=e^{\alpha(w+l)}$. Hence, if $\alpha=0$ we have EU, if $\alpha>0$ then larger outcomes get more weight, and if $\alpha<0$ larger outcomes get less weight.

\subsection{Prospect theory}

According to prospect theory (Tversky and Kahneman 1992), the value of a gamble $X$ that offers a gain $g>0$ with probability $p$ and a loss $l<0$ with probability $1-p$ is

$$
P T(X \mid r)=d^{+} u(g \mid r)+d^{-} u(l \mid r)=h^{+}(p) u(g \mid r)+h^{-}(1-p) u(l \mid r),
$$

where $d^{+}$and $d^{-}$are the gain and loss decision weights, respectively, $h^{+}$and $h^{-}$ are the gain and loss probability weighting functions, respectively, $u$ is the gain-loss utility, and $r$ represents some fixed referent, usually the status-quo.

There are different definitions of loss aversion in the literature and it is still not clear which one is the best (see Schmidt and Zank 2005; Abdellaoui et al. 2007). Here we follow Köbberling and Wakker's (2005) definition, which assumes that $u(x \mid r)$ is a composition of a loss aversion index $\lambda>0$, reflecting the different processing of gains and losses, and basic utility of gains and losses. Formally,

$$
u(x \mid r)= \begin{cases}u^{+}(x \mid r) & \text { if } \quad x \geq r \\ -\lambda u^{-}(-x \mid r) & \text { if } \quad x<r\end{cases}
$$

where $u^{+}$is the basic utility from gains and $u^{-}$the basic utility from losses. If people pay more attention to losses, $\lambda$ exceeds 1 , and $u$ is steeper for losses than for gains. ${ }^{6}$

\footnotetext{
6 The function $u$ has a kink at $r$ and is smooth everywhere else. The kink is caused by loss aversion, and does not reflect an intrinsic value of outcomes. That is, it is plausible that the basic utility function is differentiable at $r$. Thus, they define the loss aversion index as $\lambda=u_{\uparrow}^{\prime}(x \mid r) / u_{\downarrow}^{\prime}(x \mid r)$, where $u_{\uparrow}^{\prime}(x \mid r)$ denotes the left, and $u_{\downarrow}^{\prime}(x \mid r)$ the right derivative of $u$ at $r$ (both derivatives are assumed to exist and be positive and finite). If the loss aversion index is equal to 1 , there is no loss aversion. If the index is greater than 1 , the agent is loss averse.
} 
To estimate the PT model, we take $r=0, u(0 \mid 0)=0$, and we adopt the exponential specification to parameterize the basic utility of gains

$$
u^{+}(x \mid 0)=\left\{\begin{array}{ll}
\frac{1-e^{-\beta^{+} x}}{\beta^{+}}, & \beta^{+} \neq 0 \\
x, & \beta^{+}=0
\end{array},\right.
$$

and the basic utility of losses

$$
u^{-}(-x \mid 0)= \begin{cases}\frac{1-e^{-\beta^{-}(-x)}}{\beta^{-}}, & \beta^{-} \neq 0 \\ -x, & \beta^{-}=0\end{cases}
$$

The parameters, $\beta^{+}$and $\beta^{-}$, determine basic utility of gains and losses, respectively. When $\beta^{+}$and $\beta^{-}$are positive, there is diminishing sensitivity to outcomes since $u(x \mid 0)$ is concave over gains and convex over losses. When $\beta^{+}$and $\beta^{-}$are negative, there is increasing sensitivity to outcomes since $u(x \mid 0)$ is convex over gains and concave over losses. Under (4.3) and (4.3) both the utility for gains and the utility for losses have derivative 1 at 0 and, thus, the basic utility functions are differentiable at 0. Consequently, Köbberling and Wakker's (2005) definition of loss aversion can be computed under exponential utility. The exponential specification also has the desirable feature that if $\lambda \geq 1$, then we have not only loss aversion in the sense of Köbberling and Wakker (2005), but also loss aversion in the sense of Kahneman and Tversky (1979), that is, for any gain $x,-U(-x \mid r) \geq U(x \mid r)$.

As before, we adopt Goldstein and Einhorn's (1987) specification to parameterize probability weighting. Here we will consider two specifications. The first specification, PT1, has the same probability weighting parameter $\eta$ for gains and for losses. The second specification, PT2, is more flexible and allows the degree of probability weighting to be different in the gain and loss domains $\left(\eta^{+}\right.$and $\eta^{-}$, respectively). When $\eta^{+}$and $\eta^{-}$are both less than unity, there is inverse s-shape probability distortion over gains and losses. When $\eta^{+}$and $\eta^{-}$are both greater than unity, there is s-shape probability distortion over gains and losses.

\subsection{Salience theory}

According to salience theory (Bordalo et al. 2012), the value of a gamble $X$ that offers a gain $g>0$ with probability $p$ and a loss $l<0$ with probability $1-p$ is

$$
S T(X \mid r)=d^{+} u(g \mid r)+d^{-} u(l \mid r),
$$

where $d^{+}$and $d^{-}$are the gain and loss decision weights, respectively, $u$ is the gainloss utility, and $r$ represents the reference point. To estimate the ST model, we take $r=0, u(0 \mid 0)=0$, and we adopt the exponential specification in (4.3) and (4.3) to parameterize the basic utility of gains and losses, respectively. The gain decision weight is given by 


$$
d^{+}=\frac{p\left(\delta^{+}\right)^{k_{g}}}{p\left(\delta^{+}\right)^{k_{g}}+(1-p)\left(\delta^{+}\right)^{k_{l}}},
$$

and the loss decision weight by

$$
d^{-}=\frac{(1-p)\left(\delta^{-}\right)^{k_{l}}}{(1-p)\left(\delta^{-}\right)^{k_{l}}+p\left(\delta^{-}\right)^{k_{g}}} .
$$

In the above expressions, the parameters, $\delta^{+}$and $\delta^{-}$, measure the extent to which salience distorts the gain and loss decision weights, respectively, capturing the degree of local thinking. When $\delta^{+}$and $\delta^{-}$are both equal to 1 , decision weights coincide with objective probabilities. When $\delta^{+}$and $\delta^{-}$are below 1 , however, the decision maker is a local thinker, namely, she overweights the most salience states and underweights the least salient states. The gain and loss salience rankings, $k_{g}$ and $k_{l}$, follow from the gain and loss salience functions

$$
\sigma(g, 0)=\frac{|g-0|}{|g|+|0|+\zeta}
$$

and

$$
\sigma(l, 0)=\frac{|l-0|}{|l|+|0|+\zeta}
$$

where $\zeta=1$. When $\sigma(g, 0)>\sigma(l, 0)$ then $k_{g}=1<2=k_{l}$. When $\sigma(g, 0)<\sigma(l, 0)$ then $k_{g}=2>1=k_{l}$. When $\sigma(g, 0)=\sigma(l, 0)$ then $k_{g}=1=k_{l}$. As in PT, we will consider two ST specifications. The first specification, ST1, has the same $\delta$ for gains and for losses whereas the second specification, ST2, allows $\delta$ to be different in the gain and loss domains ( $\delta^{+}$and $\delta^{-}$, respectively).

\section{Estimation strategy}

This section presents our estimation strategy. First, it briefly discusses the random utility approach we apply for estimating the decision models' parameters. Subsequently, it introduces the finite mixture specification to account for EU and non-EU preferences.

\subsection{Random utility approach}

To estimate the different decision models' parameters, we follow McFadden's (1981) random utility approach for discrete choices. Consider a subject whose behavior is described by decision model $\mathrm{M} \in\{\mathrm{EU}, \mathrm{RDU}, \mathrm{WU}, \mathrm{PT}, \mathrm{ST}\}$. The subject's utility from accepting or rejecting the lottery $O \in\{a, r\}$, at a given decision,

$$
\mathcal{U}_{\mathrm{M}}\left(O ; \theta_{\mathrm{M}}, \gamma_{\mathrm{M}}\right)=U_{\mathrm{M}}\left(O ; \theta_{\mathrm{M}}\right)+\epsilon_{O},
$$


is random and consists of option $O$ 's deterministic utility $U_{\mathrm{M}}\left(O ; \theta_{\mathrm{M}}\right)$ as well as an i.i.d. random variable $\epsilon_{O}$. The random variable $\epsilon_{O}$ represents noise in the subject's utility evaluation. It follows a type 1 extreme value distribution with scale parameter $1 / \gamma_{\mathrm{M}}$. The vector $\theta_{\mathrm{M}}$ contains model M's behavioral parameters.

If $\mathcal{U}_{\mathrm{M}}\left(O=a ; \theta_{\mathrm{M}}, \gamma_{\mathrm{M}}\right) \geq \mathcal{U}_{\mathrm{M}}\left(O=r ; \theta_{\mathrm{M}}, \gamma_{\mathrm{M}}\right)$, the subject accepts the lottery. Hence, the conditional probability of accepting the lottery is given by

$$
\begin{aligned}
\operatorname{Pr}\left(O=a \mid \theta_{\mathrm{M}}, \gamma_{\mathrm{M}}\right) & =\operatorname{Pr}\left[U_{\mathrm{M}}\left(O=a ; \theta_{\mathrm{M}}\right)-U_{\mathrm{M}}\left(O=r ; \theta_{\mathrm{M}}\right) \geq \epsilon_{r}-\epsilon_{a}\right] \\
& =\frac{\exp \left[\gamma_{\mathrm{M}} U_{\mathrm{M}}\left(O=a ; \theta_{\mathrm{M}}\right)\right]}{\exp \left[\gamma_{\mathrm{M}} U_{\mathrm{M}}\left(O=a ; \theta_{\mathrm{M}}\right)\right]+\exp \left[\gamma_{\mathrm{M}} U_{\mathrm{M}}\left(O=r ; \theta_{\mathrm{M}}\right)\right]} .
\end{aligned}
$$

Note that the parameter $\gamma_{\mathrm{M}}$ governs the choice sensitivity toward differences in deterministic utility. If $\gamma_{\mathrm{M}}$ is 0 , the subject chooses each option with probability $50 \%$ regardless of the deterministic utility it provides. If $\gamma_{\mathrm{M}}$ is arbitrarily large, the probability of choosing the option with the higher deterministic utility approaches 1 .

The subject's contribution to the random utility model's density function follows directly from the product of the above conditional probabilities over all decisions:

$$
f_{\mathrm{M}}\left(O ; \theta_{\mathrm{M}}, \gamma_{\mathrm{M}}\right)=\prod_{i=1}^{10} \prod_{j=1}^{3} \operatorname{Pr}\left(O_{i j}=a \mid \theta_{\mathrm{M}}, \gamma_{\mathrm{M}}\right)^{I\left(O_{i j}=a\right)} \cdot \operatorname{Pr}\left(O_{i j}=r \mid \theta_{\mathrm{M}}, \gamma_{\mathrm{M}}\right)^{1-I\left(O_{i j}=a\right)}
$$

where the indicator $I\left(O_{i j}=a\right)$ is 1 if the subject accepts the lottery and 0 otherwise.

Reported standard errors are clustered on subjects to account for the potential serial correlation across decisions that may result from the prize-list design.

\subsection{Finite mixture specification}

While on average observed risk-taking behavior typically contradicts expected utility theory's predictions, there is vast individual heterogeneity. In particular, previous studies found the population to be made up by a majority type who clearly deviates from EU and a minority type who behaves in line with EU.

To avoid confounds in our parameter estimates, we take this behavioral heterogeneity into account and apply the following finite mixture specification to segregate the subjects into EU and non-EU types. Ex-ante individual type-membership is unknown, i.e., we cannot observe whether a subject belongs to the EU or the non-EU type. Hence, to obtain a subject's likelihood contribution, we need to weigh her type-specific density contributions $f_{\mathrm{M}}\left(O ; \theta_{\mathrm{M}}, \gamma_{\mathrm{M}}\right)$ with the corresponding ex-ante probabilities $\pi_{E U}$ of type-membership:

$$
\ell(\Psi ; O)=\pi_{\mathrm{EU}} f_{\mathrm{EU}}\left(O ; \theta_{\mathrm{EU}}, \gamma_{\mathrm{EU}}\right)+\left(1-\pi_{\mathrm{EU}}\right) f_{\text {non-EU }}\left(O ; \theta_{\text {non-EU }}, \gamma_{\text {non-EU }}\right),
$$

where the parameter vector $\Psi=\left(\theta_{\mathrm{EU}}, \theta_{\text {non-EU }}, \gamma_{\mathrm{EU}}, \gamma_{\text {non-EU }}, \pi_{E U}\right)$ contains the EU and non-EU types' behavioral parameters as well as the unknown ex-ante probability of being an EU type. The ex-ante probability of being an EU type, $\pi_{E U}$, is the same across all subjects and corresponds to the EU type's share among the population. 
Once we obtain the finite mixture model's maximum likelihood estimates $\hat{\Psi}$, the individual ex-post probabilities of belonging to the EU type follow directly by Bayes' law: ${ }^{7}$

$$
\tau_{\mathrm{EU}}=\frac{\hat{\pi}_{\mathrm{EU}} f_{\mathrm{EU}}\left(O ; \hat{\theta}_{\mathrm{EU}}, \hat{\gamma}_{\mathrm{EU}}\right)}{\hat{\pi}_{\mathrm{EU}} f_{\mathrm{EU}}\left(O ; \hat{\theta}_{\mathrm{EU}}, \hat{\gamma}_{\mathrm{EU}}\right)+\left(1-\hat{\pi}_{\mathrm{EU}}\right) f_{\text {non-EU }}\left(O ; \hat{\theta}_{\text {non-EU }}, \hat{\gamma}_{\text {non-EU }}\right)} .
$$

These ex-post probabilities of EU type-membership allow us to classify each subject into the type that best fits her behavior given the finite mixture model's parameter estimates $\hat{\Psi}$. Furthermore, they also enable us to asses the ambiguity of the subjects' type-classification. If the finite mixture model classifies the subjects cleanly into either the EU or the non-EU type, most of these ex-post probabilities of EU type-membership are either close to 1 or close to 0 , respectively. However, if the finite mixture model fails to come up with a unambiguous classification, many subjects exhibit a $\tau_{E U}$ close to $1 / 2$. We therefore inspect the distribution of these ex-post probabilities of EU type-membership to assess the finite mixture model's performance in classifying the subjects into the EU and non-EU types.

In total, we estimate six such finite mixture specifications each using a different behavioral model for the non-EU type: Two non-reference-dependent models, RDU and WU, as well as four reference-dependent models, PT1, PT2, ST1, and ST2.

\section{Results}

In this section we present and discuss our findings. We explain and present the results of our model selection strategy. Afterward, we present and interpret the estimation results.

\subsection{Model selection}

To select the model with the best descriptive power, we first compare the log likelihood values of all models that share the same number of parameters. Subsequently, we apply the integrated complete likelihood criterion (ICL) to select the best fitting model among the remaining candidates that differ in the number of parameters. We start by comparing the descriptive power of six finite mixture models versus the six pooled models. After that, within the group of finite mixture models, we compare the reference-dependent to the non- reference-dependent models.

\footnotetext{
7 Note that the above individual likelihood contribution is highly non-linear even after taking logs. Maximizing the finite mixture model's likelihood is therefore not trivial and standard numerical maximization techniques, such as the BFGS algorithm for example, will usually fail in finding its global maximum. We therefore apply Dempster et al's (1977) expectation maximization (EM) algorithm to obtain the model's maximum likelihood estimates $\hat{\Psi}$. Instead of maximizing the finite mixture model's complete log likelihood, the EM algorithm proceeds iteratively in two steps: In the E-step, it computes the individual ex-post probabilities of type-membership given the actual fit of the model. In the subsequent M-step, the EM algorithm updates the model's fit using these ex-post probabilities to maximize each type's log likelihood contribution separately.
} 
Table 6 Integrated complete likelihood for model selection

\begin{tabular}{lrl}
\hline & Mixture models & Pooled models \\
\hline \multicolumn{2}{l}{ Reference-dependent } & models \\
PT1 & $2,705.435$ & $3,346.132$ \\
PT2 & $2,640.207$ & $3,353.295$ \\
ST1 & $2,688.582$ & $3,303.387$ \\
ST2 & $2,681.154$ & $3,311.029$ \\
Non-reference-dependent models & \\
RDU & $2,780.694$ & $3,453.561$ \\
WU & $3,059.138$ & $3,630.937$ \\
\hline
\end{tabular}

The ICL is a criterion to select among finite mixture models with different numbers of type $C$, a task where classical model selection criteria such as the Akaike information criterion (AIC) and the Bayesian information criterion (BIC) may perform badly (Biernacki et al. 2000; McLachlan and Peel 2000) ${ }^{8}$. The ICL penalizes the BIC for the entropy in the classification of subjects into types:

$$
\mathrm{ICL}=\mathrm{BIC}-2 \sum_{i=1}^{N} \sum_{c=1}^{C} \tau_{i c} \ln \tau_{i c}
$$

Note that the entropy is low if the finite mixture model unambiguously classifies each subject into one type, i.e., when all $\tau_{i c}$ are either close to 0 or close to 1 . The entropy is high, on the other hand, if the classification of subjects into types is ambiguous and many subjects exhibit $\tau_{i c}$ close to $1 / C$. In the pooled model with $C=1$ type, the ICL coincides with the BIC as the entropy is zero. The model with the best descriptive power exhibits the lowest ICL.

The columns in Table 6 display the ICL for the pooled and the corresponding mixture models. In the rows are the six different specifications for non-EU behavior: PT1, PT2, ST1, ST2, RDU, and WU. In each row, the corresponding specification is used in the pooled model and in the finite mixture model's non-EU group (see Sect. 5.2.

The values in the table show that the ICL prefers the finite mixture models that control for EU and non-EU behavior over the pooled models. This is in line with previous evidence that there is heterogeneity in individual risk attitudes and that this heterogeneity may be characterized by an EU type and a non-EU type (Bruhin et al. (2010) and Conte et al. (2011)). The pooled models for non-EU behavior ignore this heterogeneity. Consequently, their parameter estimates do not correctly reflect the non-EU subjects' average behavior since they are confounded by the presence of EU subjects (the estimates of the pooled models are available upon request).

\footnotetext{
${ }^{8}$ Lo et al. (2001) proposed a statistical test (LMR-test) to select among finite mixture models with varying numbers of types, which is based on Vuong's (1989) test for non-nested models. However, the LMR-test is unlikely to be suitable when the alternative is a single-type model with strongly non-normal outcomes (Muthén 2003).
} 
Table 6 also shows that within the group of finite mixture models, referencedependent models always perform better than non-reference ones. The finding supports the idea that reference-dependence is the most important deviation from EU. Within the group of reference-dependent finite mixture models, PT and ST perform almost equally well, and models with sign-dependent decision weights (PT2 and ST2) perform better than those without (PT1 and ST1). Within the group of non-referencedependent finite mixture models, RDU performs better than WU. Given these results, we will focus on interpreting the estimates of the reference-dependent finite mixture models in the remainder of the paper. For the interested reader, the parameter estimates of the non-reference-dependent finite mixture models are presented in an Appendix at the end of the paper. Furthermore, the appendix also shows that we arrive at the same results if we select among the models based on the AIC or BIC instead of the ICL.

\subsection{Estimation results}

In this section, we report and interpret the estimation results of the reference-dependent finite mixture models. We first compare the segregation into the EU and non-EU types before interpreting the estimates of the behavioral parameters.

The parameter estimates for the PT and ST models are displayed in Tables 7 and 8, respectively. The tables show that at the aggregate level approximately one half of the subjects can be classified as EU and the other half as non-EU. The tables also show that we find the same aggregate proportion of EU types irrespective of the alternative models.

At the individual level, subjects are cleanly segregated into either EU or non-EU types. This clean segregation of subjects into types is reflected by the subjects' posterior probabilities of EU type-membership, $\tau_{\mathrm{EU}}$, obtained from (5.2). Figure 1 reports the distribution of $\tau_{\mathrm{EU}}$ obtained from the four finite mixture models.

The two panels on the top show the $\tau_{\mathrm{EU}}$ for the models where non-EU types have PT1 and PT2 preferences. The two panels on the bottom report the $\tau_{\mathrm{EU}}$ for the models where non-EU types have ST1 and ST2 preferences. In each of the four panels, we see that almost all subjects get unambiguously classified as either EU ( $\tau_{\mathrm{EU}}$ close to 1 ) or non-EU ( $\tau_{\mathrm{EU}}$ close to 0 ). There are only very few subjects with an ambiguous classification, i.e., $\tau_{\mathrm{EU}}$ in the vicinity of $1 / 2$. Moreover, the four models yield essentially the same segregation of types at the individual level: 53 (52) subjects are classified as EU types and 56 (57) as non-EU by the ST1 and PT1 (ST2 and PT2) models.

Like Bruhin et al. (2010) and Conte et al. (2011) we also find a majority of nonEU types. In contrast to these two studies, we find a higher proportion of EU types: $50 \%$ versus around $20 \%$. This difference might arise from the fact that in our study subjects only have to decide whether they accept or reject two-outcome lotteries, the simplest possible choice under risk involving both gains and losses. The other studies involved more complex decisions. In Bruhin et al. (2010), subjects had to choose between a sure amount and a two-outcome gamble involving only gains or only losses at various probability levels. In Conte et al. (2011), subjects made choices between two three-outcome gambles involving only gains at various probability levels. 
Table 7 PT mixture models' parameter estimates

\begin{tabular}{|c|c|c|c|c|}
\hline & \multicolumn{2}{|c|}{ EU-PT1 model } & \multicolumn{2}{|c|}{ EU-PT2 model } \\
\hline & EU & PT1 & EU & PT2 \\
\hline \multirow[t]{2}{*}{$\pi$} & 0.481 & 0.519 & 0.477 & 0.523 \\
\hline & $(0.077)$ & $(0.077)$ & $(0.062)$ & $(0.062)$ \\
\hline \multirow[t]{2}{*}{$\beta$} & 0.0041 & & $0.0044^{*}$ & \\
\hline & $(0.0026)$ & & $(0.0025)$ & \\
\hline \multirow[t]{2}{*}{$\beta^{+}$} & & 0.0100 & & $0.0415^{* * *}$ \\
\hline & & $(0.0150)$ & & $(0.0126)$ \\
\hline \multirow[t]{2}{*}{$\beta^{-}$} & & $0.0179^{* *}$ & & $0.0157^{* * *}$ \\
\hline & & $(0.0079)$ & & $(0.0052)$ \\
\hline \multirow[t]{2}{*}{$\eta$} & & $0.6487^{\dagger \dagger}$ & & \\
\hline & & $(0.0658)$ & & \\
\hline \multirow[t]{2}{*}{$\eta^{+}$} & & & & $0.2036^{\dagger \dagger \dagger}$ \\
\hline & & & & $(0.1481)$ \\
\hline \multirow[t]{2}{*}{$\eta^{-}$} & & & & 0.8846 \\
\hline & & & & $(0.0936)$ \\
\hline \multirow[t]{2}{*}{$\lambda$} & & 0.9079 & & $0.8716^{\dagger}$ \\
\hline & & $(0.1043)$ & & $(0.0760)$ \\
\hline \multirow[t]{2}{*}{$\gamma$} & $1.2786^{* * *}$ & $0.9882^{* * *}$ & $1.3899^{* *}$ & $1.2417^{* * *}$ \\
\hline & $(0.5934)$ & $(0.2514)$ & $(0.4935)$ & $(0.1764)$ \\
\hline$L L$ & $-1,477.858$ & & $-1,438.898$ & \\
\hline No. par. & 8 & & 9 & \\
\hline No. subj. & 109 & & 109 & \\
\hline No. obs. & 3,270 & & 3,270 & \\
\hline
\end{tabular}

Stars (daggers) indicate coefficients that are significantly different from $0(1)$ at the following levels: $*, \dagger$ $10 \%, * *,+5 \%, * * *, \dagger \dagger 1 \%$.

Across all models there is some evidence for the EU subjects being risk averse since the estimate of $\beta$ is positive and either marginally significant or insignificant. The preferences of non-EU subjects are characterized by three features: (1) the shape of the basic utility over gains and losses (parameters $\beta^{+}$and $\beta^{-}$), (2) the decision weights $\left(\eta, \eta^{+}\right.$, and $\eta^{-}$for PT and $\delta, \delta^{+}$, and $\delta^{-}$for ST), and (3) the loss aversion index $(\lambda)$.

For the models without sign-dependent decision weights, PT1 and ST1, we obtain (i) linear utility over gains since $\beta^{+}$is not significantly different from 0 and convex utility over losses since $\beta^{-}$is significantly greater than 0 , (ii) inverse s-shape probability weighting for PT1 since $\eta$ is significantly less than 1, (iii) non-linear context-dependent probability weights since $\delta$ is significantly less than 1 , (iv) loss neutrality for PT1 since $\lambda$ is not significantly different from 1 , and (v) loss seeking for ST1 since $\lambda$ is significantly less than 1 . 
Table 8 ST mixture models' parameter estimates

\begin{tabular}{|c|c|c|c|c|}
\hline & EU-ST1 mo & & EU-ST2 mo & \\
\hline & $\mathrm{EU}$ & ST1 & $\mathrm{EU}$ & ST2 \\
\hline$\pi$ & 0.486 & 0.514 & 0.478 & 0.522 \\
\hline & $(0.061)$ & $(0.061)$ & $(0.066)$ & $(0.066)$ \\
\hline$\beta$ & $0.0041^{*}$ & & 0.0044 & \\
\hline & $(0.0021)$ & & $(0.0029)$ & \\
\hline$\beta^{+}$ & & 0.0099 & & $0.0285^{*}$ \\
\hline & & $(0.0188)$ & & $(0.0163)$ \\
\hline$\beta^{-}$ & & $0.0104^{* *}$ & & 0.0050 \\
\hline & & $(0.0048)$ & & $(0.0051)$ \\
\hline$\delta$ & & $0.3885^{\dagger \dagger \dagger}$ & & \\
\hline & & $(0.0645)$ & & \\
\hline$\delta^{+}$ & & & & $0.1598^{\dagger \dagger \dagger}$ \\
\hline & & & & $(0.0711)$ \\
\hline$\delta^{-}$ & & & & 0.9999 \\
\hline & & & & $(0.0607)$ \\
\hline$\lambda$ & & $0.6368^{\dagger \dagger}$ & & 0.8511 \\
\hline & & $(0.1532)$ & & $(0.1579)$ \\
\hline$\gamma$ & $1.2883^{* *}$ & $0.5417^{* * *}$ & $1.3876^{* *}$ & $0.5358^{* * *}$ \\
\hline & $(0.5340)$ & $(0.1085)$ & $(0.6575)$ & $(0.0794)$ \\
\hline$L L$ & $-1,467.634$ & & $-1,461.164$ & \\
\hline No. par. & 8 & & 9 & \\
\hline No. subj. & 109 & & 109 & \\
\hline No. obs. & 3,270 & & 3,270 & \\
\hline
\end{tabular}

Stars (daggers) indicate coefficients that are significantly different from $0(1)$ at the following levels: $*, \dagger$ $10 \%, * *,+5 \%, * * *, \dagger \dagger 1 \%$.

For the models with sign-dependent decision weights, PT2 and ST2, we find (i) diminishing sensitivity to monetary gains and losses (s-shaped gain-loss utility function) for PT2, (ii) diminishing sensitivity to monetary gains and constant sensitivity to losses for ST2, (iii) inverse s-shape probability weighting in the gain domain and linear probability weighting in the loss domain for PT2, (iv) non-linear contextdependent probability weights in the gain domain and linear context-dependent probability weights in the loss domain and (v) (slight) loss seeking for PT2 and loss neutrality for ST2. Overall, PT and ST yield similar results, which is not surprising since the main goal of the lottery choice task is not to discriminate between these two theories through special lotteries for which they make different predictions.

Generally, these parameter estimates are plausible given the existing literature. Studies that report utility curvature for gains and losses find that utility for losses displays diminishing sensitivity in most cases but losses are evaluated more linearly than gains. Bruhin et al. (2010) and Conte et al. (2011) also find evidence of inverse 
PT1

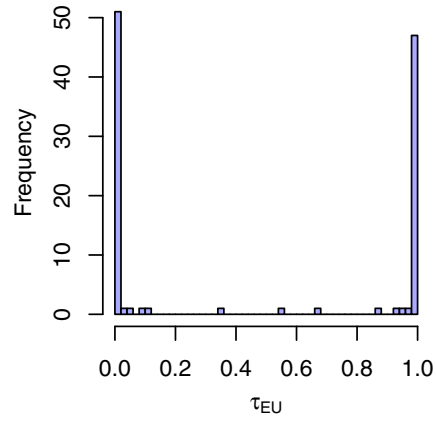

ST1

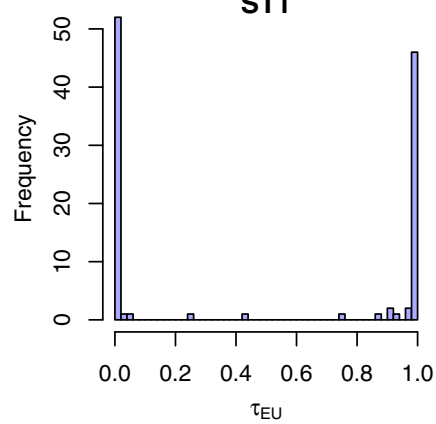

PT2

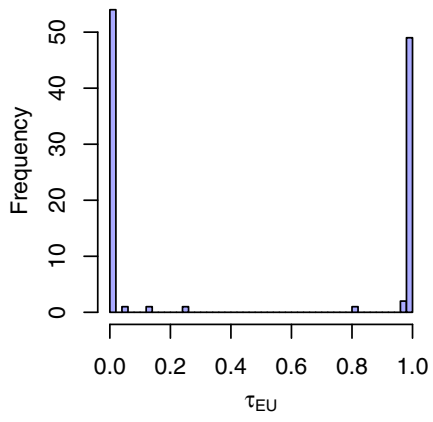

ST2

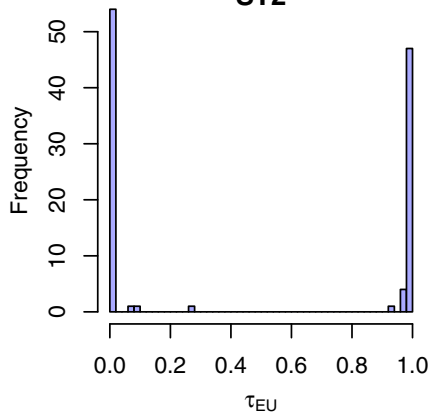

Fig. 1 Distribution of individual probabilites of EU-type-membership

s-shape probability weighting in their non-EU samples. ${ }^{9}$ We also find more upweighting of low probabilities for gains than for losses like Fehr-Duda et al. (2010). Finally, our subjects do not display loss aversion. This result is consistent with Ert and Erev (2010), and Fehr-Duda et al. (2010) as well as some field evidence (e.g., Barseghyan et al. 2010), but stands in contrast to the many studies which interpret rejection of fiftyfifty gain-loss gambles with positive mean as loss aversion (e.g., Gächter et al. 2007). Our results support the idea that loss aversion is volatile and depends on framing (see Wakker 2010, p. 265).

\section{Conclusion}

We propose a task to elicit attitudes toward risk that is sufficiently simple and compact to be easily used in field or lab experiments where risk elicitation is not the main experiment.

\footnotetext{
9 The finding is also consistent with evidence from field studies. For example, both Snowberg and Wolfers (2010) and Jullien and Salanié (2000) find that inverse s-shape probability weighting dominates in explaining why there is overbetting on the long-shot horse while favorites are underbet. In the context of insurance choices, Cohen and Einav (2007) and Barseghyan et al. (2010) find preferences in which inverse s-shape probability weighting plays the most important role.
} 
Our elicitation of risk attitudes is done with mixed gambles. This allows us to discriminate between the two main classes of alternatives to EU: reference-dependent models where utility is defined over gains and losses relative to a reference point (e.g., PT and ST) and non-reference-dependent ones where utility is defined over final outcomes (e.g., RDU and WU). The use of mixed gambles also allows us to estimate the PT and ST models in their fully specified forms, i.e., accounting for referencedependent utility functions, sign-dependent decision weights and loss aversion. We obtain the following main results.

First, individual behavior is heterogeneous with roughly $50 \%$ of the subjects behaving as EU maximizers and $50 \%$ as non-EU maximizers, and these proportions are mostly robust to the consideration of different alternatives to EU. This result reinforces the idea that the measurement of risk attitudes should take preference heterogeneity into account. This heterogeneity, as other research has suggested and our data confirm, implies that basing risk preference elicitation procedures on a single preference theory is inappropriate and may lead to biased results.

Second, models where subjects evaluate utilities relative to a reference point outperform models where subjects derive utility from final wealth outcomes. In particular, PT and ST describe behavior better than non-reference-dependent alternatives such as RDU and WU which only assume non-linear decision or outcome weights.

Acknowledgments We thank James Cox, Erik Eyster, Glenn Harrison, Botond Koszegi, and Peter Wakker for various comments and suggestions. We also thank seminar and conference participants at HEC Paris, University of Lausanne, University Jaume I Castellon, Economic Science Association World Meeting in Copenhagen, International Meeting on Behavioral and Experimental Economics in Barcelona, D-TEA Workshop in Paris, and the 68th European Meetings of the Econometric Society in Toulouse. Support from HEC Paris Foundation, Swiss National Science Foundation grant 135602, NOVA FORUM, and Fundação para a Ciência e Tecnologia is gratefully acknowledged.

\section{Appendix}

Table 9 reports the parameter estimates of the mixture models where the non-EU have RDU or WU preferences, respectively.

Figure 2 displays the probabilities of EU-type-membership for the two models. We see that both models cleanly segregate subjects into the two types. In the model where the non-EU types have WU preferences, we find 58 EU subjects and 51 nonEU subjects. In the model where the non-EU types have RDU preferences, we find 55 EU subjects and 54 non-EU subjects. In contrast to the reference-dependent models, however, the individual classifications of the non-reference-dependent models differ considerably: the RDU and the WU models only classify 54 out of the 109 subjects into the same types. Table 10 reports likelihoods for the BIC and AIC information criteria. 
Table 9 Parameter estimates of non-reference-dependent mixture models

\begin{tabular}{|c|c|c|c|c|}
\hline & \multicolumn{2}{|c|}{ EU-RDU model } & \multicolumn{2}{|c|}{ EU-WU model } \\
\hline & EU & RDU & EU & WU \\
\hline \multirow[t]{2}{*}{$\pi$} & 0.505 & 0.495 & 0.553 & 0.447 \\
\hline & $(0.095)$ & $(0.095)$ & $(0.054)$ & $(0.054)$ \\
\hline \multirow[t]{2}{*}{$\beta$} & -0.002 & $0.0082^{* * *}$ & $0.0039^{* * *}$ & $0.0096^{* *}$ \\
\hline & $(0.0019)$ & $(0.0026)$ & $(0.0010)$ & $(0.0039)$ \\
\hline \multirow[t]{2}{*}{$\eta$} & & $0.787^{\dagger \dagger \dagger}$ & & \\
\hline & & $(0.0401)$ & & \\
\hline \multirow[t]{2}{*}{$\alpha$} & & & & $1.5822^{* * *}$ \\
\hline & & & & $(0.0064)$ \\
\hline \multirow[t]{2}{*}{$\gamma$} & $0.4983^{* * *}$ & $2.2317^{* * *}$ & $1.2986^{* * *}$ & $0.1561^{* *}$ \\
\hline & $(0.1310)$ & $(0.4594)$ & $(0.1800)$ & $(0.0637)$ \\
\hline$L L$ & $-1,515.559$ & & $-1,660.461$ & \\
\hline No. par. & 6 & & 6 & \\
\hline No. subj. & 109 & & 109 & \\
\hline No. obs. & 3,270 & & 3,270 & \\
\hline
\end{tabular}

Stars (daggers) indicate coefficients that are significantly different from 0 (1) at the following levels: $*, \dagger$ $10 \%, * *, \dagger 5 \%, * *,+\dagger \dagger 1 \%$.

Table 10 BIC and AIC

\begin{tabular}{|c|c|c|c|c|}
\hline & \multicolumn{2}{|c|}{ Mixture models } & \multicolumn{2}{|c|}{ Pooled models } \\
\hline & BIC & AIC & BIC & AIC \\
\hline \multicolumn{5}{|c|}{ Reference-dependent models } \\
\hline PT1 & $3,020.455$ & $2,971.715$ & $3,346.132$ & $3,315.670$ \\
\hline PT2 & $2,950.629$ & $2,895.796$ & $3,353.295$ & $3,316.740$ \\
\hline ST1 & $3,000.007$ & $2,951.267$ & $3,303.387$ & $3,272.924$ \\
\hline $\mathrm{ST} 2$ & $2,995.161$ & $2,940.328$ & 3,311.029 & 3, 274.474 \\
\hline \multicolumn{5}{|c|}{ Non-reference-dependent models } \\
\hline RDU & $3,079.673$ & $3,043.118$ & $3,453.561$ & $3,435.283$ \\
\hline WU & $3,369.477$ & $3,332.921$ & $3,630.937$ & $3,612.659$ \\
\hline
\end{tabular}

\section{Experimental material: detecting heterogeneous risk attitudes with mixed gambles}

Research Study.

Decision Making under Risk.

Instructions.

Read these instructions carefully as your understanding of them will affect your ability to earn money.

Your decision sheet shows a table with ten decisions listed on the left. Each decision is a choice between "Accept" and "Reject" the lottery. If you Accept the lottery you 

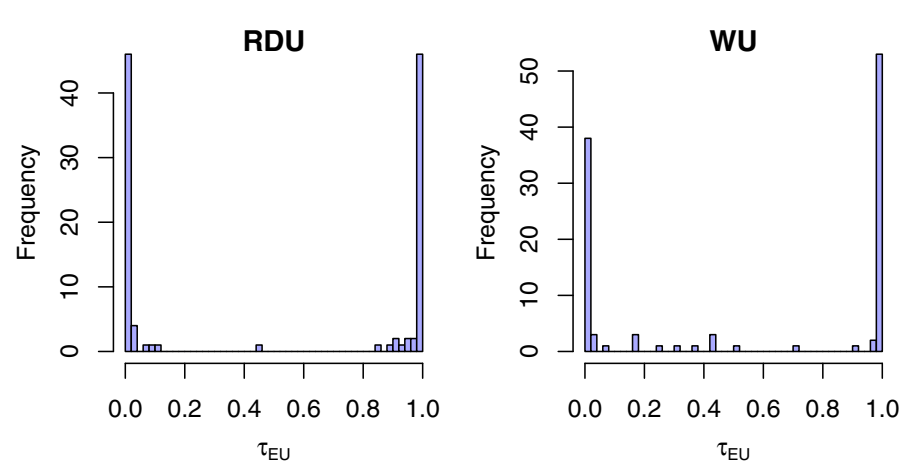

Fig. 2 Distribution of individual probabilites of EU-type-membership

have the chance of either winning or losing some money. If you Reject the lottery, you will not earn anything and you will not lose anything-your payoff will be zero.

You will make ten choices and record these by ten check marks, but only one of them will be used in the end to determine your earnings. Before you start making your ten choices, please let me explain how these choices will affect your earnings for this part of the experiment.

We will use a ten-sided die to determine payoffs; the faces are numbered from 1 to 10 (the " 0 " face of the die will serve as 10.) After you have made all of your choices, we will throw this die twice, once to select one of the ten decisions to be used, and a second time to determine your payoff if you chose "Accept" for that lottery.

Even though you will make ten decisions, only one of these will end up affecting your earnings, but you will not know in advance which decision will be used. Obviously, each decision has an equal chance of being used in the end.

Now, please look at Decision 1 at the top of Example Problem Set on the next page (Table 11). If you Accept the lottery, you will earn 50.00 CHF if the throw of the ten-sided die is 1 , and you will lose 5.00 CHF if the throw is $2-10$. The other Decisions are similar, except that as you move down the table, the value of the highest payoff decreases. For each Decision, you are asked to choose whether or not you want to take the gamble by checking the Accept or Reject columns.

This table is just an example and is not to be used to make real decisions. The problems for which you will be asked to make decisions have a similar structure, but the magnitudes of the gains and losses will be different, as well as the numbers on the dies that will determine if you make a gain or a loss.

Your gains-You may win or lose money if you Accept the lottery. If you win, you will be paid the amount won; if you lose you will have to pay the amount lost. The maximum amount that you can lose in the gambles is CHF 65. However, because we do not want you to end with less money than you started out you will be given CHF 65 from which we will deduct any loss that you may experience. In addition, you will be paid an additional CHF 15 as a compensation for your time spent.

There will be a total of three problem sets (A B, and C), each composed of ten decisions. In each problem set, the gains, losses and chances to win will be different. In the end, we will only use one of the three problem sets to determine your 
Table 11 Example problem set (not to be used for actual decisions)

\begin{tabular}{|c|c|c|c|}
\hline Decision & Lottery & Accept & Reject \\
\hline 1 & $\begin{array}{l}50 \mathrm{CHF} \text { if the throw of the die is } 1 \\
-5 \mathrm{CHF} \text { if the throw of the die is } 2-10\end{array}$ & & \\
\hline 2 & $\begin{array}{l}45 \mathrm{CHF} \text { if the throw of the die is } 1 \\
-5 \mathrm{CHF} \text { if the throw of the die is } 2-10\end{array}$ & & \\
\hline 3 & $\begin{array}{l}40 \mathrm{CHF} \text { if the throw of the die is } 1 \\
-5 \mathrm{CHF} \text { if the throw of the die is } 2-10\end{array}$ & & \\
\hline 4 & $\begin{array}{l}35 \mathrm{CHF} \text { if the throw of the die is } 1 \\
-5 \mathrm{CHF} \text { if the throw of the die is } 2-10\end{array}$ & & \\
\hline 5 & $\begin{array}{l}30 \mathrm{CHF} \text { if the throw of the die is } 1 \\
-5 \mathrm{CHF} \text { if the throw of the die is } 2-10\end{array}$ & & \\
\hline 6 & $\begin{array}{l}25 \mathrm{CHF} \text { if the throw of the die is } 1 \\
-5 \mathrm{CHF} \text { if the throw of the die is } 2-10\end{array}$ & & \\
\hline 7 & $\begin{array}{l}20 \mathrm{CHF} \text { if the throw of the die is } 1 \\
-5 \mathrm{CHF} \text { if the throw of the die is } 2-10\end{array}$ & & \\
\hline 8 & $\begin{array}{l}15 \mathrm{CHF} \text { if the throw of the die is } 1 \\
-5 \mathrm{CHF} \text { if the throw of the die is } 2-10\end{array}$ & & \\
\hline 9 & $\begin{array}{l}10 \mathrm{CHF} \text { if the throw of the die is } 1 \\
-5 \mathrm{CHF} \text { if the throw of the die is } 2-10\end{array}$ & & \\
\hline 10 & $\begin{array}{l}5 \mathrm{CHF} \text { if the throw of the die is } 1 \\
-5 \mathrm{CHF} \text { if the throw of the die is } 2-10\end{array}$ & & \\
\hline
\end{tabular}

earnings. The choice of which problem set to use to determine earnings will be made using a six-sided die. Each problem set has the same probability of being chosen. If the outcome of the six-sided die is either 1 or 2 , problem set A counts, if the outcome is either 3 or 4 set B counts, and if the outcome is either 5 or 6 set C counts.

To summarize, in each problem set, you will make ten choices: for each choice, you will have to decide between Accept or Reject the lottery. You may choose Accept for some decisions and Reject for other decisions, and you may change your decisions and make them in any order. When you are finished with making all ten choices, you will move on to the next problem set. This will be repeated three times. After the three problem sets are done, we will ask you a few demographic questions about yourself.

At the end, a randomly chosen participant will first cast a six- sided die, numbered from 1 to 6 , and then a 10-sided die, numbered 0 to 9 to select the decision which determines your earnings. The 6-sided die will decide which problem will be used, and the 10-sided die will decide which decision will be used to determine your gains or losses. The same participant will then throw the 10-sided die again to choose whether you win or lose on that lottery if you decided to Accept that lottery. You will be paid all earnings in cash when finished.

Are there any questions? Now you may begin making your choices. Please, do not talk with anyone while we are doing this; raise your hand if you have a question. 


\section{Problem set A}

\section{Instructions}

Your decision sheet shows ten decisions listed on the left (Table 12). Each decision is a choice between "Accept" and "Reject" the lottery. If you Accept the lottery, you have the chance of either winning or losing some money. If you Reject the lottery, you will not earn anything and you will not lose anything-your payoff will be zero.

You will make ten choices and record these by ten check marks, but only one of them will be used in the end to determine your earnings.

In this problem set, the gains and losses associated to each choice is different from before. Also, note that whether there will be gains or losses may be determined by different numbers on the dice. Once you have completed your choices you will move on to the next problem set. Earnings will be determined at the end of the study.

Please check whether you Accept or Reject each lottery.

Table 12 Problem set A

\begin{tabular}{|c|c|c|c|}
\hline Decision & Lottery & Accept & Reject \\
\hline 1 & $\begin{array}{l}70 \mathrm{CHF} \text { if the throw of the die is } 1 \\
-5 \mathrm{CHF} \text { if the throw of the die is } 2-10\end{array}$ & & \\
\hline 2 & $\begin{array}{l}65 \mathrm{CHF} \text { if the throw of the die is } 1 \\
-5 \mathrm{CHF} \text { if the throw of the die is } 2-10\end{array}$ & & \\
\hline 3 & $\begin{array}{l}60 \mathrm{CHF} \text { if the throw of the die is } 1 \\
-5 \mathrm{CHF} \text { if the throw of the die is } 2-10\end{array}$ & & \\
\hline 4 & $\begin{array}{l}55 \mathrm{CHF} \text { if the throw of the die is } 1 \\
-5 \mathrm{CHF} \text { if the throw of the die is } 2-10\end{array}$ & & \\
\hline 5 & $\begin{array}{l}50 \mathrm{CHF} \text { if the throw of the die is } 1 \\
-5 \mathrm{CHF} \text { if the throw of the die is } 2-10\end{array}$ & & \\
\hline 6 & $\begin{array}{l}45 \mathrm{CHF} \text { if the throw of the die is } 1 \\
-5 \mathrm{CHF} \text { if the throw of the die is } 2-10\end{array}$ & & \\
\hline 7 & $\begin{array}{l}40 \mathrm{CHF} \text { if the throw of the die is } 1 \\
-5 \mathrm{CHF} \text { if the throw of the die is } 2-10\end{array}$ & & \\
\hline 8 & $\begin{array}{l}35 \mathrm{CHF} \text { if the throw of the die is } 1 \\
-5 \mathrm{CHF} \text { if the throw of the die is } 2-10\end{array}$ & & \\
\hline 9 & $\begin{array}{l}30 \mathrm{CHF} \text { if the throw of the die is } 1 \\
-5 \mathrm{CHF} \text { if the throw of the die is } 2-10\end{array}$ & & \\
\hline 10 & $\begin{array}{l}25 \mathrm{CHF} \text { if the throw of the die is } 1 \\
-5 \mathrm{CHF} \text { if the throw of the die is } 2-10\end{array}$ & & \\
\hline
\end{tabular}




\section{Problem set B}

\section{Instructions}

As before, your decision sheet shows ten decisions listed on the left (Table 13). Each decision is a choice between "Accept" and "Reject" the lottery. If you Accept the lottery, you have the chance of either winning or losing some money. If you Reject the lottery you will not earn anything and you will not lose anything-your payoff will be zero.

You will make ten choices and record these by ten check marks, but only one of them will be used in the end to determine your earnings.

In this problem set, the gains and losses associated to each choice is different from before. Also, note that whether there will be gains or losses may be determined by different numbers on the dice. Once you have completed your choices you will move on to the next problem set. Earnings will be determined at the end of the study.

Please check whether you Accept or Reject each lottery.

Table 13 Problem set B

\begin{tabular}{|c|c|c|c|}
\hline Decision & Lottery & Accept & Reject \\
\hline 1 & $\begin{array}{l}6 \mathrm{CHF} \text { if the throw of the die is } 1-5 \\
-1 \mathrm{CHF} \text { if the throw of the die is } 6-10\end{array}$ & & \\
\hline 2 & $\begin{array}{l}6 \mathrm{CHF} \text { if the throw of the die is } 1-5 \\
-2 \mathrm{CHF} \text { if the throw of the die is } 6-10\end{array}$ & & \\
\hline 3 & $\begin{array}{l}6 \mathrm{CHF} \text { if the throw of the die is } 1-5 \\
-3 \mathrm{CHF} \text { if the throw of the die is } 6-10\end{array}$ & & \\
\hline 4 & $\begin{array}{l}6 \mathrm{CHF} \text { if the throw of the die is } 1-5 \\
-4 \mathrm{CHF} \text { if the throw of the die is } 6-10\end{array}$ & & \\
\hline 5 & $\begin{array}{l}6 \mathrm{CHF} \text { if the throw of the die is } 1-5 \\
-5 \mathrm{CHF} \text { if the throw of the die is } 6-10\end{array}$ & & \\
\hline 6 & $\begin{array}{l}6 \mathrm{CHF} \text { if the throw of the die is } 1-5 \\
-6 \mathrm{CHF} \text { if the throw of the die is } 6-10\end{array}$ & & \\
\hline 7 & $\begin{array}{l}6 \mathrm{CHF} \text { if the throw of the die is } 1-5 \\
-7 \mathrm{CHF} \text { if the throw of the die is } 6-10\end{array}$ & & \\
\hline 8 & $\begin{array}{l}6 \mathrm{CHF} \text { if the throw of the die is } 1-5 \\
-8 \mathrm{CHF} \text { if the throw of the die is } 6-10\end{array}$ & & \\
\hline 9 & $\begin{array}{l}6 \mathrm{CHF} \text { if the throw of the die is } 1-5 \\
-9 \mathrm{CHF} \text { if the throw of the die is } 6-10\end{array}$ & & \\
\hline 10 & $\begin{array}{l}6 \mathrm{CHF} \text { if the throw of the die is } 1-5 \\
-10 \mathrm{CHF} \text { if the throw of the die is } 6-10\end{array}$ & & \\
\hline
\end{tabular}


Table 14 Problem set C

\begin{tabular}{|c|c|c|c|}
\hline Decision & Lottery & Accept & Reject \\
\hline 1 & $\begin{array}{l}-20 \mathrm{CHF} \text { if the throw of the die is } 1 \\
5 \mathrm{CHF} \text { if the throw of the die is } 2-10\end{array}$ & & \\
\hline 2 & $\begin{array}{l}-25 \mathrm{CHF} \text { if the throw of the die is } 1 \\
5 \mathrm{CHF} \text { if the throw of the die is } 2-10\end{array}$ & & \\
\hline 3 & $\begin{array}{l}-30 \mathrm{CHF} \text { if the throw of the die is } 1 \\
5 \mathrm{CHF} \text { if the throw of the die is } 2-10\end{array}$ & & \\
\hline 4 & $\begin{array}{l}-35 \mathrm{CHF} \text { if the throw of the die is } 1 \\
5 \mathrm{CHF} \text { if the throw of the die is } 2-10\end{array}$ & & \\
\hline 5 & $\begin{array}{l}-40 \mathrm{CHF} \text { if the throw of the die is } 1 \\
5 \mathrm{CHF} \text { if the throw of the die is } 2-10\end{array}$ & & \\
\hline 6 & $\begin{array}{l}-45 \mathrm{CHF} \text { if the throw of the die is } 1 \\
5 \mathrm{CHF} \text { if the throw of the die is } 2-10\end{array}$ & & \\
\hline 7 & $\begin{array}{l}-50 \mathrm{CHF} \text { if the throw of the die is } 1 \\
5 \mathrm{CHF} \text { if the throw of the die is } 2-10\end{array}$ & & \\
\hline 8 & $\begin{array}{l}-55 \mathrm{CHF} \text { if the throw of the die is } 1 \\
5 \mathrm{CHF} \text { if the throw of the die is } 2-10\end{array}$ & & \\
\hline 9 & $\begin{array}{l}-60 \mathrm{CHF} \text { if the throw of the die is } 1 \\
5 \mathrm{CHF} \text { if the throw of the die is } 2-10\end{array}$ & & \\
\hline 10 & $\begin{array}{l}-65 \mathrm{CHF} \text { if the throw of the die is } 1 \\
5 \mathrm{CHF} \text { if the throw of the die is } 2-10\end{array}$ & & \\
\hline
\end{tabular}

\section{Problem set C}

\section{Instructions}

As before, your decision sheet shows ten decisions listed on the left (Table 14). Each decision is a choice between "Accept" and "Reject" the lottery. If you Accept the lottery, you have the chance of either winning or losing some money. If you Reject the lottery, you will not earn anything and you will not lose anything-your payoff will be zero.

You will make ten choices and record these by ten check marks, but only one of them will be used in the end to determine your earnings.

In this problem set, the gains and losses associated to each choice is different from before. Also, note that whether there will be gains or losses may be determined by different numbers on the dice. Once you have completed your choices you will move on to the next problem set. Earnings will be determined at the end of the study.

Please check whether you Accept or Reject each lottery.

\section{References}

Abdellaoui, M. (2000). Parameter-free elicitation of utility and probability weighting functions. Management Science, 46, 1497-1512. 
Abdellaoui, M., Bleichrodt, H., \& Paraschiv, C. (2007). Loss aversion under prospect theory: A parameterfree measurement. Management Science, 53, 1659-1674.

Abdellaoui, M., Bleichrodt, H., \& L'Haridon, O. (2008). A tractable method to measure utility and loss aversion under prospect theory. Journal of Risk and Uncertainty, 36, 245-266.

Barseghyan, L., Molinari, F., O’Donoghue, T., \& Teitelbaum, J. (2010). The nature of risk preferences: Evidence from insurance choices, Working paper, SSRN.

Biernacki, C., Celeux, G., \& Govaert, G. (2000). Assessing a mixture model for clustering with the integrated completed likelihood. IEEE Transactions on Pattern Analysis and Machine Intelligence, 22(7), 719725.

Bordalo, P., Gennaioli, N., \& Shleifer, A. (2012). Salience theory of choice under risk. Quarterly Journal of Economics, 127(3), 1243-1285.

Brunner, T., Levinsky, R., \& Qiu, J., (2007). A note on skewness seeking: An experimental analysis," Jena Economic Research Papers, 079.

Bruhin, A., Fehr-Duda, H., \& Epper, T. (2010). Risk and rationality: Uncovering heterogeneity in probability distortion. Econometrica, 78(4), 1375-1412.

Cohen, A., \& Einav, L. (2007). Estimating risk preferences from deductible choice. The American Economic Review, 97(3), 745-788.

Conte, A., Hey, J., \& Moffat, P. (2011). Mixture models of choice under risk. Journal of Econometrics, 162(1), 79-82.

Deck, C., \& Schlesinger, H. (2010). Exploring higher-order risk effects. Review of Economic Studies, 77, 1403-1420.

Dempster, A. P., Laird, N. M., \& Rubin, D. B. (1977). Maximum likelihood from incomplete data via the EM Algorithm. Journal of the Royal Statistical Society Series B, 39, 1-38.

Ebert, S., \& Wiesen, D. (2009). An experimental methodology for testing for prudence and third-order preferences, Bonn Econ Discussion Papers, 21.

El-Gamal, M., \& Grether, D. (1995). Are people Bayesian? Uncovering behavioral strategies. Journal of the American Statistical Association, 90, 1137-1145.

Ert, E., \& Erev, I. (2010). On the descriptive value of loss aversion under risk, Working paper, Harvard Business School.

Falk, A., \& Heckman, J. (2009). Lab experiments are a major source of knowledge in the social sciences. Science, 326(5952), 535-538.

Fehr-Duda, H., Bruhin, A., Epper, T., \& Schubert, R. (2010). Rationality on the rise: Why relative risk aversion increases with stake size. Journal of Risk and Uncertainty, 40(2), 147-180.

Gächter, S., Johnson, E., \& Herrmann, A. (2007). Individual-level loss aversion in riskless and risky choices, Centre for Decision Research and Experimental Economics Discussion Paper Series, ISSN 1749-3293.

Goldstein, W., \& Einhorn, H. (1987). Expression theory and the preference reversal phenomena. Psychological Review, 94, 236-254.

Greiner, B. (2004). An online recruiting system for economic experiments. In K. Kremer \& V. Macho (Eds.), Forschung und wissenschaftliches Rechnen 2003. GWDG Bericht 63 (pp. 79-93). Göttingen: Ges. für Wiss.

Harrison, G., \& Rutström, E. (2009). Expected utility theory and prospect theory: One wedding and a decent funeral. Experimental Economics, 12, 133-158.

Hey, J., \& Orme, C. (1994). Investigating generalizations of expected utility theory using experimental data. Econometrica, 62(6), 1291-1326.

Holt, C., \& Laury, S. (2002). Risk aversion and incentive effects. American Economic Review, 92(5), 1644-1655.

Hong, C. S. (1983). A generalization of the quasilinear mean with applications to the measurement of income inequality and decision theory resolving the Allais Paradox. Econometrica, 51(4), 1065-1092.

Houser, D., \& Winter, J. (2004). How do behavioral assumptions affect structural inference? Journal of Business and Economic Statistics, 22, 64-79.

Houser, D., Keane, M., \& McCabe, K. (2004). Behavior in a dynamic decision problem: An analysis of experimental evidence using a Bayesian type classification algorithm. Econometrica, 72, 781-822.

Jullien, B., \& Salanié, B. (2000). Estimating preferences under risk: The case of racetrack bettors. Journal of Political Economy, 108(3), 503-530.

Kahneman, D., \& Tversky, A. (1979). Prospect theory: An analysis of decision making under risk. Econometrica, 47, 263-292.

Köbberling, V., \& Wakker, P. (2005). An index of loss aversion. Journal of Economic Theory, 122, 119-131. 
Lattimore, P. K., Baker, J. R., \& Witte, A. D. (1992). The influence of probability on risky choice. Journal of Economic Behavior and Organization, 17, 377-400.

Levitt, S., \& List, J. (2007). What do laboratory experiments measuring social preferences reveal about the real world? The Journal of Economic Perspectives, 21(2), 153-174.

Lo, Y., Mendell, N. R., \& Rubin, D. B. (2001). Testing the number of components in a normal mixture. Biometrika, 88, 767-778.

McFadden, D. (1981). Econometric models of probabilistic choice. In C. Manski \& D. McFadden (Eds.), Structural analysis of discrete data with econometric applications. Cambridge, MA: MIT Press.

McLachlan, G., \& Peel, D. (2000). Finite mixture models., Wiley series in probabilities and statistics New York: Wiley.

Muthén, B. (2003). Statistical and substantive checking in growth mixture modeling: Comment on Bauer and Curran (2003). Psychological Methods, 8(3), 369-377.

Quiggin, J. (1982). A theory of anticipated utility. Journal of Economic Behavior and Organization, 3, $323-343$.

Schmidt, U., \& Zank, H. (2005). What is loss aversion? Journal of Risk and Uncertainty, 30, 157-167.

Schoemaker, P. (1982). The expected utility model: It's variants purposes, evidence and limitations. Journal of Economic Literature, 20, 529-563.

Snowberg, Eric., \& Wolfers, Justin. (2010). Explaining the favorite-longshot bias: Is risk love or misperceptions? Journal of Political Economy, 118(4), 723-746.

Stahl, D., \& Wilson, P. (1995). On players' models of other players: Theory and experimental evidence. Games and Economic Behavior, 10, 218-254.

Starmer, C. (2000). Developments in non-expected utility theory: The hunt for a descriptive theory of choice under risk. Journal of Economic Literature, 38, 332-382.

Tanaka, T., Camerer, C. F., \& Nguyen, Q. (2010). Risk and time preferences: Experimental and household survey data from Vietnam. The American Economic Review, 100(1), 557-571.

Tversky, A., \& Kahneman, D. (1992). Advances in prospect theory: Cumulative representation of uncertainty. Journal of Risk and Uncertainty, 5, 297-323.

Vuong, Q. H. (1989). Likelihood ratio tests for model selection and non-nested hypotheses. Econometrica, 57, 307-333.

Wakker, P. (2010). Prospect theory for risk and uncertainty. New York: Cambridge University Press. 